\title{
Foliar and Axial Aspects of Vascular Differentiation: Hypotheses and Evidence
}

\author{
Roni Aloni* \\ Department of Plant Sciences, Tel Aviv University, Tel Aviv 69978, Israel
}

\begin{abstract}
A comparison is made between foliar and axial vascular differentiation. Current thoughts and new evidence are presented on the role of hormones in controlling the differentiation of vascular tissues in organized and tumorous tissues, focusing on the role of auxin and cytokinin in controlling phloem and xylem relationships, vessel size and density, cambium sensitivity, vascular adaptation and xylem evolution in deciduous hardwood trees. The possible role of wounding is also considered. A new hypothesis, namely, the leaf-venation hypothesis, is proposed to explain the hormonal control of vascular differentiation in leaves of dicotyledonous plants. Experimental evidence in support of the hypothesis is pre-
\end{abstract}

sented showing that hydathodes, the watersecreting glands, are the primary sites of auxin synthesis during leaf morphogenesis. Vessel element patterns similar to those found in hydathodes were experimentally induced by exogenous auxin application.

Key words: Vascular differentiation; Xylem and phloem development; Venation pattern formation; Leaf morphogenesis; Auxin and cytokinin synthesis; Ethylene and wound response; Cambium sensitivity; Arabidopsis thaliana; Cucumis sativus; Nicotiana tabacum

\section{INTRODUCTION}

There are basic differences in vascular differentiation between foliar and axial organs (Esau 1965; Sachs 1981). Vascular development along the plant axis is an open-type differentiation process persisting throughout the growth period from apical and lateral meristems (Sachs 1981; Aloni 1987; Roberts and others 1988), whereas vascular differentiation in a leaf is limited to early stages of primordium development (Mattsson and others 1999; Sieburth 1999).

The distance between the site of hormone syn-

Online publication 21 June 2001

*Corresponding author; e-mail: alonir@post.tau.ac.il thesis and the location of the differentiating vascular tissues is an important factor in the control of patterned vascular differentiation (Aloni and Zimmermann 1983; Aloni 1987, 1995). This distance may regulate auxin levels which control developmental patterns and relationship between phloem and xylem, as well as conduit size and density. The models by which we can currently explain vascular pattern formation are limited (Berleth and Mattsson 2000; Berleth and others 2000; Deyholos and others 2000; Koizumi and others 2000; Sachs 2000). There is a need for additional analysis at the molecular, cellular and organismic levels, which should be integrated for better understanding (Nelson and Dengler 1997; Sachs 2000). Moreover, there is a need to understand in more detail the role of hormonal signals 
in patterning and differentiation, their spatial distribution, and local differences in their synthesis and reception (Nelson and Dengler 1997).

The general purpose of this review is to provide an organismic explanation for how distance between the sites of hormone synthesis and the locations of differentiating vascular tissues in organs with different morphogenetic patterns controls an organized differentiation of both xylem and phloem in the entire plant. The present review provides a summary of major topics pertaining to organized and tumorous vascular differentiation and the recent advances made in each. It starts with new evidence regarding hypotheses on the control of vascular differentiation along the plant axis. As venation pattern formation in leaves is different from vascularization along the stem it requires specific explanations. In an attempt to achieve a better understanding of the general and specific hormonal mechanisms that direct and regulate vascularization in leaves, I propound a new hypothesis on the control of vascular differentiation and pattern formation in dicotyledonous leaves. I hope that the proposed leaf-venation hypothesis will stimulate the use of new molecular methods to test its applicability in Arabidopsis thaliana and other dicotyledonous species, as a challenge for imaginative students.

\section{Differentiation Along the Plant Axis}

\section{Control of Vascular Differentiation by a Signal Flow}

The plant hormone indole-3-acetic acid (IAA) is an endogenous auxin involved in all aspects of vascular differentiation (Aloni 1995, Aloni and others 2000). The continuity of vascular tissues along the plant, from the margin of leaves to the root apices, is induced by the steady polar flow of auxin from leaves to roots. The major path of auxin flow along the stems of pine and poplar trees is in the vascular cambium (Uggla and others 1996, 1998; Sundberg and others 2000). Experimental evidence indicates that the transition from procambium to cambium requires a threshold level of ethylene (Aloni and others 2000). The canalization hypothesis (Sachs 1981) proposes that auxin flow, which starts by diffusion, induces a polar auxin transport system which promotes auxin movement and leads to canalization of auxin flow along a narrow file of cells. The continuous polar transport of auxin through these cells induces a further complex series of events which finally result in the formation of a vascular strand. The canalization of auxin flux through meristematic, or parenchyma cells, induces the orderly pattern of continuous vascular strands from leaves to roots. This suggests that vascular differentiation can be used as an anatomical expression of auxin flow (Sachs 1981, 2000).

\section{Vascularization in Plant Tumors}

Until recently, plant tumors induced by Agrobacterium tumefaciens were considered unorganized or partly organized masses (Sachs 1991 and references therein). A recent analysis of the three-dimensional pattern of phloem and xylem in Agrobacterium tumefaciens-induced crown galls unveiled a sophisticated vascular network of continuous vascular strands extending from the host plant up to the tumor margin. The development of these strands indicates synthesis of auxin by the A.tumefaciens-transformed plant cells located immediately beneath the surface of the fastgrowing tumor (Aloni and others 1995). The strands in a tumor contain both xylem and phloem, and are interconnected by a dense network of phloem anastomoses, consisting of sieve tubes but not vessels. In the centripetal direction, the crown gall induces the development of pathologic xylem characterized by narrow vessels, absence of fibers and giant rays. These anatomical features have triggered the propounding of the gall-constriction hypothesis (Aloni and others 1995) to explain the mechanism which gives priority in water supply to the growing gall over the host shoot. The hypothesis proposes that a growing gall retards the development of its host shoot by decreasing vessel diameter in the shoot tissues close to the tumor, which substantially reduces water supply to the upper parts of the shoot. It was further postulated that the controlling signal that induces the narrow vessels in the host is the hormone ethylene (Aloni and others 1995), which is known to reduce vessel diameter (Yamamoto and others 1987). The gall-constriction hypothesis was experimentally confirmed by showing that tumor-induced ethylene is a limiting and controlling factor of crown gall morphogenesis; very high ethylene levels were produced continuously by a growing crown gall during a few weeks, up to 140 times more ethylene than in wounded, but not infected control stems, reaching a maximum at five weeks after infection (Aloni and others 1998; Wächter and others 1999). Tumor-induced ethylene diminished vessel diameter in the host stem and enlarged the surface (through which high transpiration occurs) of the tumor (Aloni and others 1998), thus giving priority in water supply to the growing gall over the host shoot. A recent comparison between the development of plant and animal tumors has shown an analogous requirement for neovascularization in both, presag- 
ing possible strategies for prevention and therapy (Ullrich and Aloni 2000).

\section{Relationships Between Phloem and Xylem}

Plant vascular systems are usually composed of phloem and xylem, and insofar as the relative proportions of phloem and xylem are concerned there is a major difference between foliar and axial organs. Thus, along the plant axis, xylem does not differentiate in the absence of phloem, though strands of phloem (with no xylem) and phloem anastomoses are common in stems of many plant species (Aloni and Sachs 1973; Roberts and others 1988; Aloni and Peterson 1990; Aloni and Barnett 1996). It has been suggested that the differentiation of phloem strands and phloem anastomoses between the strands is controlled by streams of low auxin levels (Aloni 1987, 1995).

Conversely, in leaves, the differentiation of xylem in the absence of phloem is a common feature and occurs in freely ending veinlets (Lersten and Brubaker 1989; Lersten 1990; Lersten and Curtis 1993; Horner and others 1994) and hydathodes (Fahn 1990). In Oxalis stricta there are virtually no sieve tubes in any terminal vein, while Polygonum convolvulus, at the other extreme, has sieve tubes extending to the tips of most terminal veins (Horner and others 1994). In most of the studied species freely ending veinlets may display disparate relations between phloem and xylem in the same plant, e.g., vein endings lacking sieve tubes or having them up to the tip, and sieve tubes that end at some intermediate point (Lersten and Brubaker 1989; Lersten 1990; Lersten and Curtis 1993; Horner and others 1994).

In tissue cultures, low auxin levels induced sieve elements but not tracheary elements, while high auxin levels resulted in the differentiation of both phloem and xylem (Aloni 1980, 1987), but even in these cultures, at the surface further away from the auxin-containing medium, only phloem with no xylem developed (Aloni 1980). High auxin concentrations applied to decapitated Luffa stems induced xylem differentiation in its phloem anastomoses (Aloni 1995) indicating the need for high hormonal stimulation for xylem differentiation. In leaves, the proximity between the sites of auxin synthesis and the site of differentiating vascular cells probably results in relatively high local auxin levels at the differentiating sites, which may explain why xylem can differentiate in the absence of phloem at the freely ending veinlets (Lersten 1990; Horner and others 1994) and hydathodes (Raven and others 1999) (see below, the leaf-venation hypothesis).
A new Arabidopsis mutant with a unique spatial relationship between phloem and xylem, forming amphivasal vascular strands (Zhong and others 1999), might offer insights regarding the relations between these vascular tissues.

\section{Control of Vessel Size and Density Along the Plant Axis}

The control of vessel diameter is an important parameter for assessing the ascent of water and minerals from roots to leaves and the adaptation of plants to their environment (Aloni 1987). The specific purpose of research in this direction is to develop a reliable concept for understanding and explaining the mechanisms that control vessel size and density (number of vessels per transverse-sectional area) along the plant. Such a concept may serve as a tool for analyzing developmental patterns of vessel size and density in different plant species (e.g., ringporous versus diffuse-porous trees) and in specific sites (e.g., hydathodes) in the vascular system, will be discussed below.

A linear increase in vessel diameter with increasing auxin concentration from $100 \mathrm{mg} / \mathrm{l}$ to $1000 \mathrm{mg} / \mathrm{l}$ (with the gibberellic acid at $100 \mathrm{mg} / \mathrm{l}$ in all cases) was found in the ring-porous species Robinia pseudoacacia (Digby and Wareing 1966). However, this increase in vessel diameter could perhaps be ascribed to the disparity in rates between gibberellic acid and auxin levels. The hypothesis, recently named the Wareing's hypothesis by Lev-Yadun (2000), proposes a positive correlation between auxin concentration and vessel diameter (Digby and Wareing 1966) is contrary to what one would expect from the overall pattern of vessel diameter along the plant axis. The narrow vessels differentiate near the leaves, where the highest auxin levels are expected, while the widest vessels are formed in the roots, at the greatest distance from the auxin sources. The increase in vessel diameter from leaves to roots is associated with a decrease in vessel density. Hence, vessel density is generally greater in branches, where the vessels are narrow, than in roots, where they are wide (Fegel 1941; Carlquist 1975, 1988).

In an attempt to resolve this apparent contradiction and better explain the general increase in vessel diameter and decrease in vessel density from leaves to roots, a six-point hypothesis (Aloni and Zimmermann 1983) has been proposed. The six point hypothesis attributes the general increase in vessel size and decrease in vessel density along the plant axis to a gradient of decreasing auxin concentration from leaves to roots. High auxin levels near the young leaves induce narrow vessels because of their rapid 
differentiation, allowing only limited time for cell growth. Contrariwise, low auxin concentrations further down result in slow differentiation, which permits more cell expansion before secondary wall deposition, and therefore results in wide vessels. Vessel density is controlled by auxin concentration, to wit: high concentrations (near the sites of auxin synthesis) induce greater density, while low concentrations (further down, towards the roots) lower density. Therefore, vessel density decreases from leaves to roots.

The validity of the six-point hypothesis (Aloni and Zimmermann 1983) was strongly contested by LevYadun (2000) who, erroneously claimed that the Aloni and Zimmermann (1983) experiment used partial girdling in which wound effect dominates (including wound ethylene). Therefore, it needs to be clarified that in the cited experiment we did not use partial girdling, but only decapitated stems on which various auxin concentrations were applied. Furthermore, the six-point hypothesis, arbitrarily renamed the Aloni-Zimmermann hypothesis by LevYadun (2000), does not deal with sensitivity and modifications in porosity following changes in growth conditions, as misconstrued by Lev-Yadun, but only explains the control of conduit size and density along the plant axis. Lev-Yadun (2000) confuses and incorrectly blends together two different hypotheses, namely, the six-point hypothesis of Aloni and Zimmermann 1983 and the limited-growth hypothesis of Aloni 1991 (see below), as if they are a united hypothesis. Lev-Yadun (2000) also debunks the effects of auxin on earlywood vessel differentiation (Aloni 1991) as resulting predominantly from wound effects, although he must be well aware that it is doubtful whether a wound effect could influence vessel diameter $50 \mathrm{~mm}$ below the site of auxin application (see Figure 8.7 in Aloni 1991). LevYadun (p. 319) writes that the experimentally induced vessel members (Aloni 1991) differentiated in narrow bridges, but shortly after (Lev-Yadun, p. 321), these vessels differentiated in decapitated stems. I maintain that only the latter claim is correct. Later on Lev-Yadun (pp. 321-322) emphasizes that the high auxin levels applied must have resulted in auxin-induced ethylene production, yet he ignores the facts that in that experiment (Figure 8.7, Aloni 1991) only extremely low auxin concentrations $(0.003 \%, 0.01 \%$, and $0.1 \% \mathrm{w} / \mathrm{w}$ naphthaleneacetic acid, NAA in lanolin) were applied to decapitated stems of Melia azedarach, and that each concentration induced a unique pattern of vessel size and density $50 \mathrm{~mm}$ below the cut (the wound). Science can only benefit from well-argued debate and thus I welcome criticism of my hypotheses and results, so long as it is accurate. In fact, a recent piece of evidence by us (Figure 3 in Aloni and others 2000) reveals that the Lev-Yadun (2000) contention is wrong. The mentioned Figure shows that the application of a very low hormonal stimulation $(0.02 \%$ $\mathrm{w} / \mathrm{w}$ in lanolin), of either gibberellin, ethylene, auxin, or only lanolin (as a control), to decapitated stems of Melia azedarach, induced specific pit patterns in the secondary wall of the vessel endings. The experiment (Figure 3, Aloni and others 2000) demonstrates that the specific secondary wall patterns in vessel endings, which differentiated in a very short distance (less than $5 \mathrm{~mm}$ ) below the cut (using the experimental method developed by Indig and Aloni 1989), were indeed induced and determined by each hormonal treatment and not by a wound effect, or wound ethylene. Even the lanolin control (in which an effect of wound ethylene could dominate) produced a very different result from that obtained by ethylene (originating from $0.02 \%$ ethrel). This evidence indicates that in our decapitated Melia stem system, the level of any possible wound ethylene was too low to exert any influence on the anatomy or size of vessel endings in less than $5 \mathrm{~mm}$ below the cut (Aloni and others 2000), or affect vessel diameter further away, at $50 \mathrm{~mm}$ below the site of auxin application (Aloni 1991).

A study on vessel regeneration along the plant axis in two Cucurbita species (Aloni and Barnett 1996) provides further evidence that the Lev-Yadun (2000) stand regarding wounding is incorrect. The study elucidates the role of both wounding and distance from the young leaves (the major auxin sources) on the diameter of regenerated vessels; we found that narrow regenerated vessels differentiated around a wound in young internodes, near the source of auxin synthesis (young leaves), whereas wide regenerated vessels (up to 5-fold wider) were frequently formed around the same type of wound in mature internodes, away from the young leaves. A similar pattern of a basipetal increase in the diameter of regenerated vessels (up to 3-fold wider) was found in spring, around the same type of wound (Aloni and Barnett 1996), along the stem of the ring-porous tree Melia azedarach (R. Aloni, unpublished). This sharp increase in regenerated vessel diameter with increasing distance from young leaves affirms that distance from the source of auxin synthesis is the major factor controlling vessel diameter, as was predicted by the six-point hypothesis (Aloni and Zimmermann 1983), and not the wound, or ethylene effect, as claimed by Lev-Yadun. We need, however, address also Lev-Yadun's (2000) impugnment of the validity of results obtained from wounding and auxin-application experiments. These experi- 
ments started with the pioneering study of Jacobs (1952) who demonstrated the role of exogenously applied auxin in xylem regeneration around a wound. That said, there is no question that wound ethylene might affect the results in wounding and exogenously applied hormone experiments. Yet, a careful investigator should always take into account the distance from a wound and the examined tissues and accordingly run control tests and treatments which should help to clarify the possible involvement of the wound or ethylene in the process.

\section{Evolution of Wood Formation in Deciduous Hardwood Trees: The Role of Cambium Sensitivity and Adaptation}

From an evolutionary standpoint, trees have developed earlier than did the specialized herbaceous species. The early evolution of deciduous woody plants, who lose their leaves and become relatively inactive physiologically during periods of extreme conditions, may have contributed to the evolutionary success of angiosperms, especially during the past 50 million years, when the global climates have been undergoing active changes (Raven and others 1999). Therefore, understanding the control mechanisms that have shaped vascular evolution in hardwoods could elucidate the roles of hormonal signaling and tissue sensitivity (Trewavas 1983; Bradford and Trewavas 1994) to inductive signals (Aloni and others 2000). For this purpose I have tried to understand vascular pattern formation within temperate deciduous hardwood trees, some of which have giant vessels which are easy to follow. In temperate deciduous hardwood trees, vessel size differences in the early- and latewoods are quite marked so that two categories of deciduous trees are recognized: diffuse-porous species and ring-porous species. In diffuse-porous wood the vessels are more or less uniform in size, whereas in ring-porous wood the vessels produced at the beginning of the growth season are significantly wider than those produced at the end of the season.

Aloni (1991) and Wheeler and Baas (1991) suggested that ring-porous trees have originated from diffuse-porous species. The development of ringporosity has probably arisen independently multiple times during the diversification of angiosperms, and different lineages might therefore have modified mechanisms for regulating development. Generally, the limited-growth hypothesis (Aloni 1991) proposes that during the evolution of temperate deciduous hardwood trees, the ring-porous species have developed from diffuse-porous species under the selective pressures of limiting environments which resulted in limited vegetative growth. It was further postulated that the natural selection for ring-porous wood has led to a decrease in the intensity of vegetative growth, accompanied by reduced auxin levels. The latter was followed by an increase in the sensitivity of the cambium to relatively low auxin stimulation (Aloni 1991).

The sensitivity of the cambium and vascular tissues is promoted by inductive stimuli originating in root apices (Aloni 1987, 1991, 1993). The major developmental signals of the roots are cytokinins, which increase the sensitivity of the vascular meristems and conductive tissues to developmental signals originating in the leaves (Aloni and others 1991, 2000; Baum and others 1991; Aloni 1995).

Lev-Yadun (2000) opposed, but with no supporting evidence, the idea proposed by Aloni (1991) that in deciduous ring-porous species the cambium had become highly sensitive owing to decreased levels of auxin stimulation, while in deciduous diffuseporous species the cambium remained less sensitive and therefore required high levels of stimulation for its operation. We have no reason to assume that evergreen and temperate deciduous hardwood trees share an identical regulatory mechanism. Therefore, Lev-Yadun (2000) cannot use porosity changes in evergreen trees to question cambium sensitivity in deciduous hardwoods. Whereas porosity modifications in deciduous hardwoods are expected and well explained by the limited-growth hypothesis (Aloni 1991; Aloni and others 2000). It is consequently important to emphasize that due to the high sensitivity of the cambium (requires extremely low auxin levels for reactivation, see below) in deciduous ringporous trees it undergoes extremely fast reactivation (early cell divisions) in the spring, which occurs almost simultaneously in the branches and trunk. This is why the bark of deciduous ring-porous trees may be peeled a few days before any bud swelling can be observed in spring. The bark can be removed along the newly formed cell layer of reactivated cambium because it possesses thin cell walls following cell divisions. Conversely, in deciduous diffuse-porous species, because their cambium is less sensitive (needs a high auxin stimulation to promote cell divisions, see below), it requires several weeks for a 'wave' of cambial reactivation to extend from the twigs of a large tree to the base of its trunk (Priestley and Scott 1936). Consequently their bark cannot be peeled during these several weeks after bud swelling because the cambium at the base of their trunk remains dormant.

When I proposed the concept of increased cambium sensitivity in deciduous ring-porous trees, as part of the limited-growth hypothesis (Aloni 1991), it 
was mostly intuition based partly on my own experience with these deciduous species. Today, there is further experimental evidence from transformed plants (Zhang and others 1995; Eklöf and others 1997) that supports the idea that reduced auxin levels can elevate cytokinin levels, which would enhance tissue sensitivity (Aloni 1991, 1993, Aloni and others 2000). The new data demonstrate that auxin or cytokinin modify the content of the other hormone by affecting its rate of synthesis. Increased auxin levels reduce free cytokinin levels and vice versa (Palni and others 1988; Zhang and others 1995; Eklöf and others 1997). Results from plants transformed with iaaM and $i a a H$ genes that overproduce auxin show lower levels of endogenous cytokinins in them than in untransformed controls (Eklöf and others 1997). Similarly, in whole plants, or in tissues transformed with the ipt gene that overproduce cytokinin, the level of free IAA and occasionally of conjugates is reduced. Inactivation of the auxinsynthesis genes (iaaM and iaaH) results in marked increase in the level of cytokinins in the transformed tissues (Zhang and others 1995). This evidence from transformed plants supports the idea that during the evolution of ring-porous trees, a decrease in auxin production promoted an increase in cytokinin levels. This, in turn, enhanced cambium sensitivity to low-level auxin streams originating in swelling buds and created the special conditions that enable the differentiation of very wide earlywood vessels during a limited period of time in spring. Only because of the heightened sensitivity of the cambium in ringporous trees (Aloni 1991, Aloni and Peterson 1997, Aloni and others 1997, 2000) their first wide earlywood vessels are initiated six to two weeks before the onset of leaf expansion (Suzuki and others 1996). Conversely, in diffuse-porous species, the first earlywood vessels are initiated two to seven weeks after the onset of leaf expansion (Suzuki and others 1996), and because of its low sensitivity, their cambium requires high auxin levels (from fastgrowing young leaves) for reactivation.

Furthermore, extremely low auxin concentrations $(0.003 \%, 0.01 \% \mathrm{w} / \mathrm{w}$ NAA in lanolin), which induced wide earlywood vessels in the deciduous ring-porous trees Robinia pseudoacacia (R. Aloni, unpublished) and Melia azedarach (Aloni 1991, Figure 8.7), did not stimulate earlywood vessel differentiation in the deciduous diffuse-porous trees Magnolia kobus and Acer saccharum (R. Aloni, unpublished). On the other hand, a high auxin concentration ( $1 \%$ w/w NAA in lanolin) promoted earlywood vessel formation in Magnolia and Acer, but prevented wide earlywood vessel formation in Robinia and Melia (R. Aloni, unpublished). Similarly, opposite responses were also found in the phloem of deciduous hardwood trees with different porosity. Thus, application of the high auxin concentration ( $1 \%$ NAA) to excised dormant branches before bud break resulted in the removal of the dormancy callose from the sieve tubes of the diffuse-porous Magnolia, but an accumulation of callose on the most recently formed sieve tubes of the deciduous ring-porous Quercus robur (Aloni and Peterson 1997), indicating that the ring-porous tree is extremely sensitive and the high auxin applied constitutes an overdose for its phloem.

Our recent xylem-regeneration experiments (A. Wolf and R. Aloni, unpublished) on tobacco plants transformed with either iaaM, or iaaL genes, which respectively overproduce auxin (up to 7.3-fold increase) in 19S-iaaM plants, or substantially reduce endogenous IAA (by up to 19-fold) in 35S-iaaL plants (Romano and others 1991), affirm the reports that increased auxin levels reduce free cytokinin levels and vice versa (Zhang and others 1995; Eklöf and others 1997). Xylem regeneration around a wound in young internodes of wild-type and in the transformed tobacco plants (Romano and others 1991) with intact leaves, was remarkably similar in all the various lines, even with the very high, or extremely low endogenous IAA levels (A. Wolf and R. Aloni, unpublished). Furthermore, no differences between the lines were observed regarding xylem regeneration, when the leaves above the wound were replaced by a low auxin $(0.1 \% \mathrm{w} / \mathrm{w}$ NAA in lanolin) source. However, when a high auxin (1\% NAA $\mathrm{w} / \mathrm{w}$ in lanolin) source replaced the apical leaves, elevated xylem regeneration occurred in the wild-type and in the transformed plants with low endogenous IAA levels, albeit there was no xylem regeneration around the wound in the auxinoverproducing plants (19S-iaaM plants with a 7.3fold increase in IAA level), probably because the latter treatment induced an excess of auxin stimulation upon the iaaM plants. When the leaves above the wound were replaced by lanolin (with no auxin), no xylem regeneration occurred in the wild-type or the 35S-iaaL plants (Romano and others 1991), but did occur in the auxin-overproducing plants (19S-iaaM plants) (Figure 1). These experiments on xylem regeneration in tobacco plants transformed with either iaaM, or iaaL genes, demonstrate that changes in the endogenous auxin levels result in the adaptation of the transformed tissues to the modified endogenous auxin levels. This adaptation means that in the auxin-overproducing plants the vascular tissues become less sensitive to auxin. On the other hand, in the transformed plants with extremely low endogenous auxin levels, there is a substantial increase in 


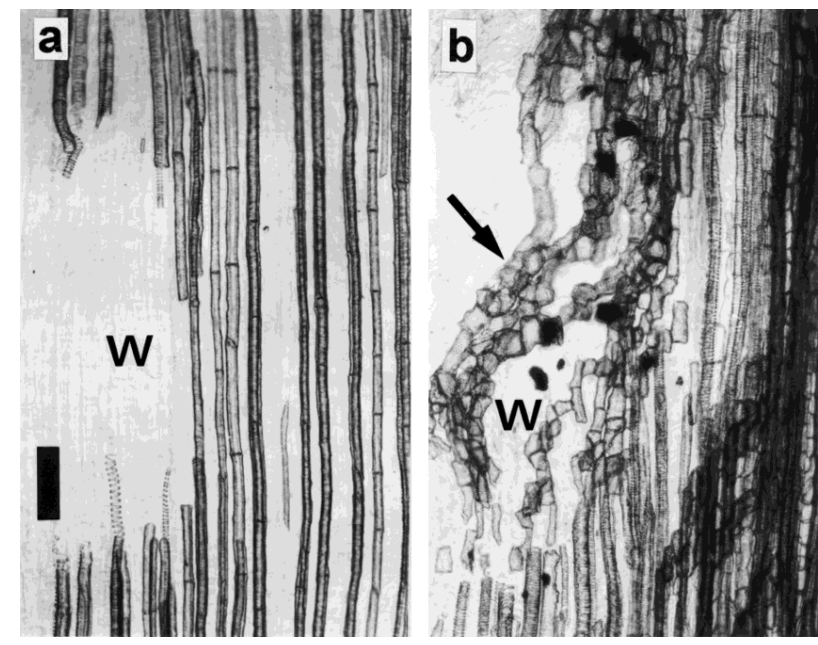

Figure 1. Longitudinal views of wounds $(W)$ in young internodes of (a) wild-type and (b) auxin-overproducing (by 7.3-fold in line: 19S-iaaM 1, vide Romano and others 1991) Nicotiana tabacum plants. The tissues were taken from decapitated internodes treated for 7 days with lanolin (with no auxin). The tissues were cleared in pure lactic acid and were left unstained. The experiment was repeated three times. The photomicrographs show the absence of xylem regeneration in the wild-type plant (a), and the typical xylem regeneration (arrow) in the overproducing auxin plant (b). Scale bar $=200 \mu \mathrm{m}$. (A. Wolf and R. Aloni, unpubl.).

the sensitivity of the vascular tissues to the reduced level of the signal. This experimental evidence is consistent with the idea that during the evolution of temperate deciduous hardwood trees, selective pressures in limiting environments, which restricted vegetative growth, reduced auxin levels in the developing ring-porous trees, the latter promoted an increase in sensitivity of the cambium to relatively low auxin stimulation (Aloni 1991).

\section{DifFERENTIATION IN LEAVES}

\section{Control of Vascular Pattern Formation in Leaves: The Leaf-venation Hypothesis}

Most plants exhibit slight to considerable heteroblasty, where the leaves produced at different stages of shoot development vary in their morphology. In the model organism Arabidopsis thaliana (Meyerowitz 1989), the vegetative shoot is composed mainly of rosette leaves. Hence, understanding of leaf morphogenesis and vascular differentiation in this species is very important for correct evaluation of its mutants and their gene function. Early rosette leaves of Arabidopsis have rounded blades with smooth margins, while leaves produced in later stages of shoot development have slightly serrated edges (Poething 1997). Molecular mechanisms determining leaf architecture in compound leaves have been elucidated in tomato (Hareven and others 1996) and pea (Gourlay and others 2000). However, mechanisms that control the morphogenesis of leaf margins are poorly understood (Groot and Meicenheimer 2000). Controlling factors that may affect leaf development and tissue differentiation along the plant axis are physiological gradients, which are induced by moving signals such as auxin and cytokinin. These hormones may promote gradual changes in organ development and tissue differentiation. A gradient of auxin, with higher concentrations in proximal than in distal regions was detected in young tobacco leaves (Edlund and others 1995), probably resulting from auxin accumulation above the leaf base.

Leaves are characterized by complex networks of vascular tissues (Sachs 1975, 1981, 1989; Nelson and Dengler 1997; Candela and others 1999), fast vascular development and early determination (Mattsson and others 1999). Regeneration of both leaf shape (Sachs 1969) and leaf vascular differentiation is limited to early developmental stages (Sachs 1975, 1981; Mattsson and others 1999; Sieburth 1999).

In complex networks of leaves, there are strands in which the individual cells do not have an obvious shoot-to-root polarity and therefore can be deemed not polar (Sachs 1975). It has been suggested that during the process of strand differentiation the strand axis is determined first and along this axis auxin movement may occur in opposite directions (Sachs 1975, 1981, 1989).

In wild-type plants, discontinuities in the path of xylem differentiation were detected during the process of vascular differentiation in their developing leaves (Esau 1965). In defective mutants such vascular discontinuities may also be visualized in mature cotyledons and leaves (Przemeck and others 1996; Candela and others 1999; Carland and others 1999; Deyholos and others 2000; Hobbie and others 2000; Koizumi and others 2000).

In leaves, vascular tissues become progressively confined to the leaf margin as the concentration of auxin transport inhibitors is increased, suggesting that the leaf vascular system depends on inductive signals from the margin of the leaf (Mattsson and others 1999; Sieburth 1999). Staged application of auxin transport inhibitors has demonstrated that primary, secondary and tertiary veins become unresponsive to further modulations of auxin transport at successive stages of early leaf development, indicating that the pattern of primary and secondary 
strands becomes fixed at the onset of lamina expansion (Mattsson and others 1999; Sieburth 1999).

The molecular and physiological mechanisms that govern and determine venation pattern formation in leaves are poorly understood (Telfer and Poething 1994; Nelson and Dengler 1997; Nelson 1998; Candela and others 1999; Carland and others 1999; Mattsson and others 1999; Sieburth 1999; Deyholos and others 2000). In order to clarify where auxin synthesis occurs in dicotyledonous plant leaves, and how the production sites and the auxin levels control vascular differentiation in these leaves, I propose the following leaf-venation hypothesis:

1. The expanding tissues of a leaf primordium are the sites where auxin is synthesized. Fast-growing regions are the major locations of auxin production. The term 'leaf apical dominance' is now proposed to describe, within a developing leaf, how the fastgrowing tip of a primordium produces auxin which suppresses the synthesis of auxin in the leaf tissues below it. Along the plant axis, this tip-inhibition effect may diminish with increasing distance of a leaf primordium from the root apices, the diminution due to declining levels of root-induced cytokinins with increasing distance from the root.

2. The rapidly elongating tip of a growing primordium is the first major site of auxin synthesis in a leaf. The auxin produced by the tip and expanding leaf periphery is drained basipetally into the stem. However, developmental patterns (R. Aloni, unpublished) suggest that the leaf/stem junction is a local barrier which slows down auxin flow at the junction. Within a leaf, the junctions between the midvein (primary vein) and secondary veins might also slow auxin movement and cause increasing levels of auxin concentrations above these sites. It is further proposed that during leaf development there are gradual changes in primary auxin synthesis sites along the leaf, which occur along the margins in a downward 'wave' pattern, extending from the tip to the base of the primordium. Since the tip of a leaf primordium matures relatively fast, its auxin production decreases, whereas the auxin production increases in the upper lobes, which grow faster and become the major auxin synthesis sites. Later on, when the upper lobes mature, their auxin production decreases, while auxin production now increases in the lobes below them-a process that continues downward and diminishes at the base of the leaf.

3. As primary production of auxin along the blade's margin decreases, secondary auxin synthesis sites within the lamina become relatively effective. I sug- gest that this relatively late auxin production occurs during primordium development as a result of local intercalary expansion growth, where the inner parts of the leaf expand at different rates and in different directions (Avery 1933) - a process that has been termed anisotropic growth (Ashby 1948).

4. At very early stages of primordium development the auxin levels are low and therefore only the basic framework (main strands and loops) of procambium is induced. This provascular network design determines the later patterns of xylem and phloem differentiation, which will follow the procambium configuration during leaf morphogenesis.

5. A regular feature of xylem development is the formation of discontinuous patterns during the process of differentiation (Figure 2). In other words, vessel differentiation proceeds normally in discontinuous fashion, entailing discrete vessel elements, which ultimately join into a continuous vessel. These discontinuities are formed along a differentiating vessel because the individual vessel elements have different speeds of maturation. A positive correlation is suggested between auxin level and the rate of vessel-element maturation. Differentiating vessel elements exposed to high levels of auxin, which are either near a site of auxin synthesis, or above an obstacle to auxin flow (where auxin accumulates), differentiate faster than do the other intervening vessel elements.

6. Xylem maturation patterns are determined by auxin levels and the ability of the differentiating cells to respond to the auxin signal. Fast leaf expansion results in high auxin synthesis, which promotes xylem differentiation within the basic procambium network induced early in primordium development. Auxin accumulation at the base of a leaf primordium above the leaf/stem junction obstacle, determines the acropetal pattern of xylem differentiation in the midvein. Shortly after, the high auxin levels produced at the tip and leaf margin induce xylem loops (within the already laid-down procambial pattern), which develop in the basipetal direction, away from the auxin sources. High auxin concentrations synthesized by the tip and lobes accelerate xylem differentiation in these locations, which may result in discontinuous patterns of xylem differentiation in the lobes during early stages of leaf development (Figure $2 \mathrm{~b}, \mathrm{c}$ ). The high auxin levels produced by the tip and lobes induce basipetal patterns of decreasing numbers of tracheary elements along the distal parts of the major veins, from the sites of auxin synthesis downward, resulting in the formation of hydathodes (Figure 3).

7. Phloem differentiation is induced by low-grade 

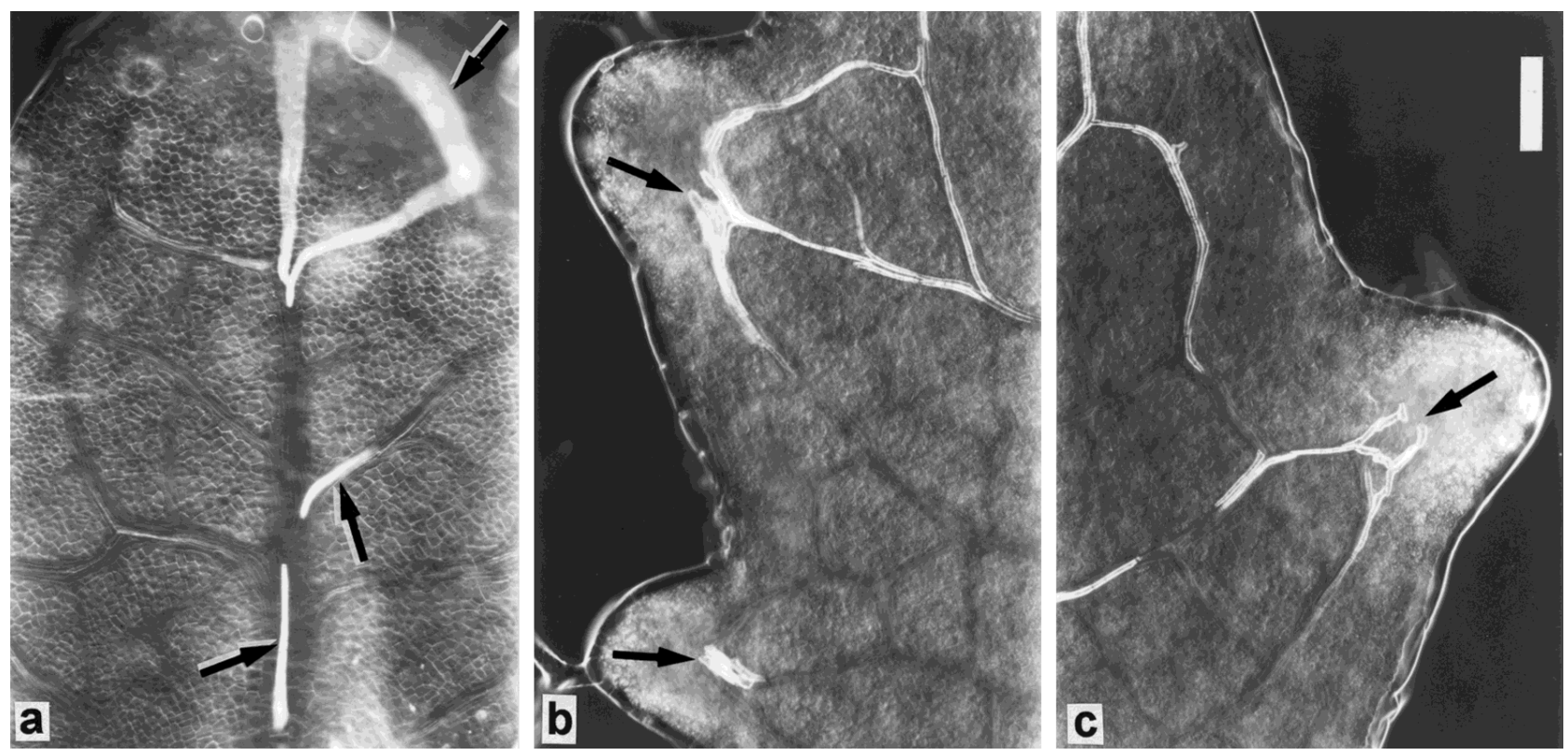

Figure 2. Naturally occurring discontinuities in the path of xylem development in intact expanding rosette leaf primordia of a wild type Arabidopsis thaliana Columbia ecotype, grown under short day conditions (8 hours light), cleared with lactic acid and photographed under Nomarski illumination. The discontinuous vessels have a white appearance and they differentiate within the provascular network which appears as the darkest tissue. (a) shows unique discontinuous patterns of vessels (marked by arrows) in an early stage of primordium development. The upper parts of a closed vessel (a loop) located beneath the apical tip are not in focus and therefore have a thick appearance. (b) and (c) show a more advanced stage of primordium development with typical discontinuities in the path of xylem differentiation, characterized by advanced vessel differentiation (arrows) in developing lobes, at the sites of hydathode formation. A very early stage of discontinuous xylem differentiation in a hydathode site is shown in (b) in the lower lobe, while in the more advanced lobe above it the vascular tissues are more developed with additional vessel elements near the lobes's tip. Scale bar $=200 \mu \mathrm{m}$.

auxin stimulation, whereas xylem differentiation requires higher auxin levels (Aloni 1980, 1987, 1995). In leaves, owing to proximity of the sites of auxin production to those of vascular differentiation, the differentiating cells are exposed to relatively high local auxin levels, which could therefore result in the differentiation of xylem in the absence of phloem in the free-ending veinlets and hydathodes. Conversely, in locations where the terminal veins are induced by relatively low auxin levels, the sieve tubes may extend to the tip of the freely ending veinlets. Intermediate sieve tube configurations are probably induced by intermediate levels of auxin. These freely ending veinlets inside a leaf are induced by secondary auxin synthesis sites produced in the lamina.

8. Due to fast development and early determination of tissues in leaves, there is a very rapid decrease in the ability of parenchyma cells in the lamina to regenerate. Consequently, vessel differentiation and regeneration here is limited to existing strands, where new vessel elements differentiate mainly from meristematic cells in the strands rather than from parenchyma cells of the early-determined lamina. Accordingly, late vessel differentiation, or regeneration, is restricted to already existing strands and might therefore occur along the same axis even in opposite polarities.

The above leaf-venation hypothesis explains the differentiation of vascular tissues in Arabidopsis thaliana and other simple-leaved dicotyledon species, which usually mature basipetally. The one reported exception not explained by the hypothesis is Quercus ru$b r a$, in which an acropetal leaf development occurs (Tomlinson and others 1991).

The former six-point hypothesis (Aloni and Zimmermann 1983) predicted that near a site of auxin synthesis many tracheary elements would differentiate and their number would decrease with increasing distance from the auxin production site. Analyzing the pattern of vessel elements in large hydathodes indeed shows a significant basipetal decrease in the number of tracheary elements as one moves away from the leaf margin. The greatest number of vessel elements in the hydathodes are formed near the leaf margin (Figure 3a) indicating that this is 

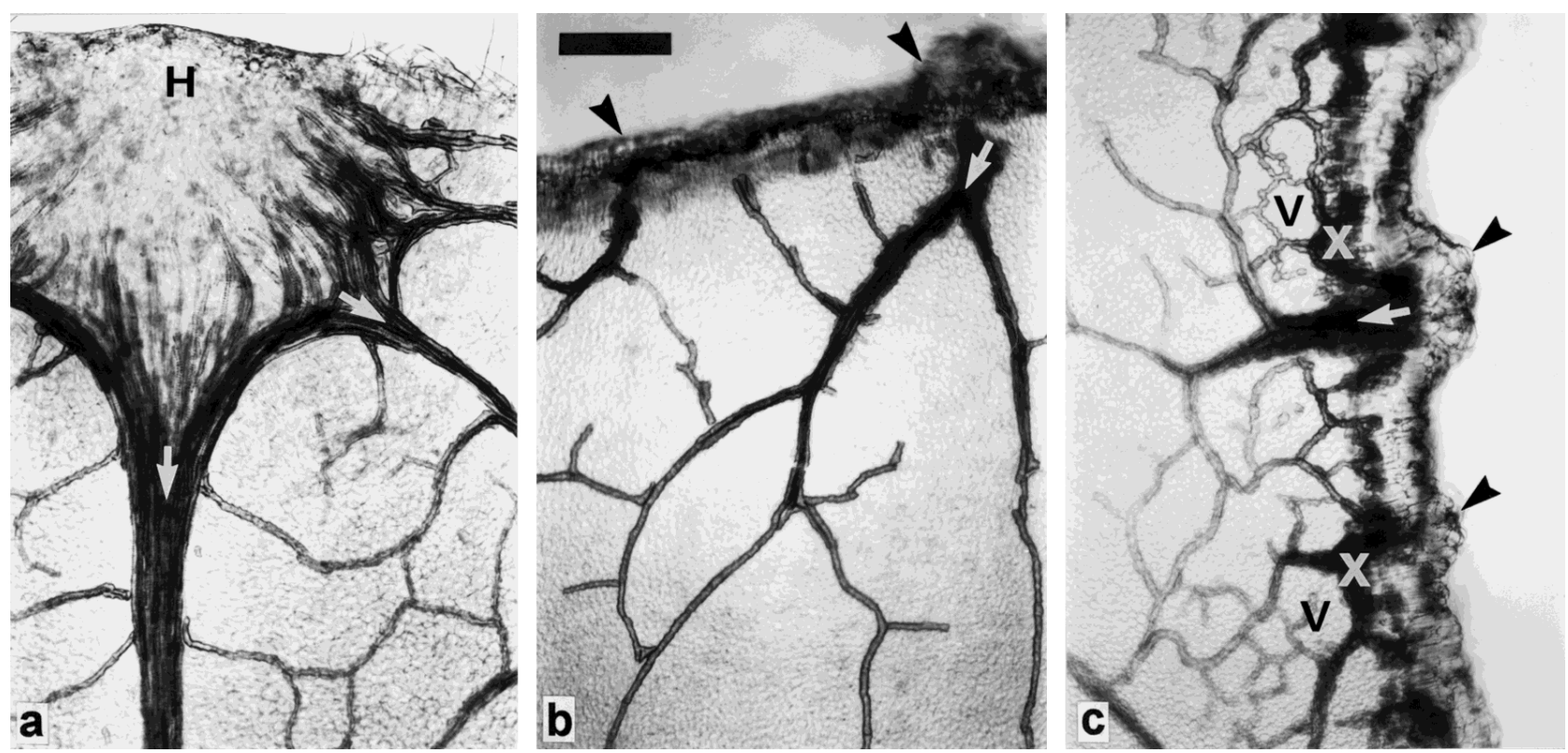

Figure 3. Naturally occurring (a) and auxin (a one-week $1 \%$ IAA, w/w in lanolin) induced (b and c) xylem patterns in young Cucumis sativus cotyledons, cleared with lactic acid and photographed under a light microscope. The experiment was repeated three times. The photomicrographs show typical basipetal gradients (marked by white arrows inside the strands) of decreasing number of vessel elements away from the center $(H)$ of the hydathode $(\mathbf{a})$, from the horizontal (b), and from the longitudinal (c) cuts to which the IAA was applied (arrowheads). These cuts were made away from the hydathode in very young cotyledons. Note that there are many freely ending vessels which differentiated towards the center $(H)$ of the large hydathode (a), thus indicating the location where the natural inductive signal (auxin) is produced. The applied auxin induced cell proliferation on both cut surfaces above some of the strands (b and $\mathbf{c})$. It also induced a layer of numerous xylem elements $(X)$ and increased vein density $(V)$ beneath the longitudinal cut $(\mathrm{c})$. This elevated vein density decreased with increasing distance from the cut (from the applied auxin). Scale bar $=200 \mu \mathrm{m}$. (R. Aloni and B. Rotblat, unpubl.).

where the most intensive auxin synthesis occurs. Similar patterns of basipetal decrease in vessel element density along a leaf strand were experimentally induced by an exogenous auxin source applied along a cut in a very young cotyledon (Figure 3b, c). Application of a high auxin level to a longitudinal cut made in cucumber cotyledon substantially increased vein density near the exogenous auxin source (Figure $3 \mathrm{c}$ ), thus mimicking the role of the rapidly elongating tip, the lobes and the leaf margin of a growing primordium as the major auxin synthesis sites in a leaf, causing a relatively high vein density in the distal regions of a dicotyledonous plant leaf.

Genes that are induced by auxin, might be reported by GUS expression in developing lobe tips (see Figure 4f in Plesch and others 1997) of leaf primordia where hydathodes differentiate. This expression pattern marks primary sites of auxin synthesis in developing leaf primordia. I suggest that GUS accumulation in developing hydathodes of young leaf primordia might be enhanced by auxin transport inhibitors. Genes that are positively influenced by auxin can be used for analyzing develop- mental changes in the sites of auxin synthesis during leaf morphogenesis, as suggested by the leaf-venation hypothesis. This may be best analyzed in species with relatively large leaves, like those of tobacco.

In order to identify genes determining venation pattern formation and control of vascular differentiation, mutants of Arabidopsis and other model plants are being screened for altered vascular patterns. The genetic screening may uncover mutations in genes that specifically disrupt the normal pattern of vascular differentiation (Przemeck and others 1996; Candela and others 1999; Carland and others 1999; Deyholos and others 2000; Hobbie and others 2000; Koizumi and others 2000). Discontinuities in the provascular tissues of defective mutants were detected during early stages of leaf organogenesis (Deyholos and others 2000; Koizumi and others 2000). Mutants with defective vascular patterns may fail to establish uniformly aligned vascular cells and discontinuities in the xylem occur in their mature leaves (Przemeck and others 1996; Candela and others 1999; Carland and others 1999; Deyholos and others 2000; Koizumi and others 2000). It needs to be emphasized that in the course of leaf histogenesis 
in wild-type plants, vascular discontinuities normally appear during the regular process of organized strand formation (Figure 2), but in defective mutants, however, some of the intermediate discontinuities persist as the final xylem structure in the mature leaves. In addition, novel patterns of vascular networks may emerge in defective mutants (Deyholos and others 2000; Koizumi and others 2000) indicating modifications in the auxin pathways and transport during the process of vascular differentiation. Mutants defective in the formation of continuous vascular networks may result from mutations in genes encoding components of the polar auxin transport machinery, e.g., genes causing defected basipetal transport of auxin (Carland and McHale 1996), reduced capacity of polar transport of auxin (Przemek and others 1996), and modified sensitivity to auxin (Deyholos and others 2000). Genes affecting early stages of vascular patterning, prior to provascular network formation, may promote differentiation along wide pathways rather than narrow canals, because of failures to establish efficient canals of auxin flow. An ineffective wide pathway caused by a defect in the polar auxin transport machinery may fail to establish continuous wide xylem strands and can therefore result in fragmented patterns of vascular islands (Deyholos and others 2000; Koizumi and others 2000).

Discontinuities in mature phloem, which can also be regarded as early developmental stages that have become fixed during differentiation as a result of a failure to complete the maturation process, are observed regularly in defective mutants of Arabidopsis (Przemeck and others 1996; Carland and others 1999). Such discontinuous phloem patterns have been correlated with analogous discontinuities in xylem patterns (Carland and others 1999).

In conclusion, the hypotheses and evidence discussed above indicate that auxin is the major controlling signal in vascular differentiation and patterning. Other plant hormones and their interactions should also be considered. A better molecular understanding of the polar auxin transport machinery, integrated with analyses at both the cellular and organismic levels, could clarify the general and organ-specific mechanisms which induce and regulate vascular differentiation in plants.

\section{ACKNOWLEDGMENTS}

This paper is dedicated to Prof. Tsvi Sachs for inspiration and contributions to vascular differentiation. I thank Prof. Harry J. Klee and the Monsanto Company for the gift of seeds of wild-type, 19S-iaaM and 35 -iaaL tobacco plants.

\section{REFERENCES}

Aloni R. 1980. Role of auxin and sucrose in the differentiation of sieve and tracheary elements in plant tissue cultures. Planta 150:255-263.

Aloni R. 1987. Differentiation of vascular tissues. Annu Rev Plant Physiol 38:179-204.

Aloni R. 1991. Wood formation in deciduous hardwood trees. In: Raghavendra AD, editor. Physiology of trees. New York: Wiley and Sons. p 175-197.

Aloni R. 1993. The role of cytokinin in organized differentiation of vascular tissues. Aust J Plant Physiol 20:601-608.

Aloni R. 1995. The induction of vascular tissues by auxin and cytokinin. In: Davies PJ, editor. Plant hormones: physiology, biochemistry and molecular biology, 2nd ed. Dordrecht: Kluwer Academic Publishers. p 531-546.

Aloni R, Alexander JA, Tyree MT. 1997. Natural and experimentally altered hydraulic architecture of branch junctions in Acer saccharum Marsh. and Quercus velutina Lam. trees. Trees 11:255-264. DOI: $10.1007 / \mathrm{s} 004680050083$

Aloni R, Barnett JR. 1996. The development of phloem anastomoses between vascular bundles and their role in xylem regeneration after wounding in Cucurbita and Dahlia. Planta 198:595-603.

Aloni R, Baum SF, Peterson CA. 1991. The role of cytokinin in sieve tube regeneration and callose production in wounded Coleus internodes. Plant Physiol 93:982-989.

Aloni R, Feigenbaum P, Kalev N, Rozovsky S. 2000. Hormonal control of vascular differentiation in plants: the physiological basis of cambium ontogeny and xylem evolution. In: Savidge RA, Barnett JR, Napir R, editors. Cell and molecular biology of wood formation. Oxford: BIOS Scientific Publishers. p 223236.

Aloni R, Peterson CA. 1990. The functional significance of phloem anastomoses in stems of Dahlia pinnata Cav. Planta 182:583-590.

Aloni R, Peterson CA. 1997. Auxin promotes dormancy callose removal from the phloem of Magnolia kobus and callose accumulation and earlywood vessel differentiation in Ouercus robur. J Plant Res 110:34-44.

Aloni R, Pradel KS, Ullrich CI. 1995. The three-dimensional structure of vascular tissues in Agrobacterium tumefaciens-induced crown galls and in the host stem of Ricinus communis L. Planta 196:597-605.

Aloni R, Sachs T. 1973. The three-dimensional structure of primary phloem systems. Planta 113:345-353.

Aloni R, Wolf A, Feigenbaum P, Avni A, Klee HJ. 1998. The Never ripe mutant provides evidence that tumor-induced ethylene controls the morphogenesis of Agrobacterium tumefaciensinduced crown galls on tomato stems. Plant Physiol 117:841847.

Aloni R, Zimmermann MH. 1983. The control of vessel size and density along the plant axis-a new hypothesis. Differentiation 24:203-208.

Ashby E. 1948. Studies in the morphogenesis of leaves: I. An essay on the leaf shape. New Phytol 47:153-176.

Avery Jr GS. 1933. Structure and development of tobacco leaf. Amer J Bot 20:565-592.

Baum SF, Aloni R, Peterson CA. 1991. The role of cytokinin in vessel regeneration in wounded Coleus internodes. Ann Bot 67:543-548.

Berleth T, Mattsson J. 2000. Vascular development: tracing sig- 
nals along veins. Curr Opin Plant Biol 3:406-411. DOI: 10.1016/S1369-5266(00)00104-7

Berleth T, Mattsson J, Hardtke CS. 2000. Vascular continuity and auxin signals. Trends Plant Sci 5:387-393. DOI: 10.1016/ S1360-1385(00)01725-8

Bradford KJ, Trewavas AJ. 1994. Sensitivity thresholds and variable time scales in plant hormone action. Plant Physiol 105:1029-1036.

Candela H, Martinez-Laborda A, Micol JL. 1999. Venation pattern formation in Arabidopsis thaliana vegetative leaves. Dev Biol 205:205-216. DOI: 10.1006/dbio.1998.9111

Carland FM, Berg BL, FitzGerald JN, Jinamornphongs S, Nelson T, Keith B. 1999. Genetic regulation of vascular tissue patterning in Arabidopsis. Plant Cell 11:2123-2137.

Carland FM, McHale NA. 1996. LOP1: a gene involved in auxin transport and vascular patterning in Arabidopsis. Development 122:1811-1819.

Carlquist S. 1975. Ecological strategies of xylem evolution. Berkeley: University of California Press. 258 p.

Carlquist S. 1988. Comparative wood anatomy, systematic, ecological, and evolutionary aspects of dicotyledon wood. Berlin: Springer-Verlag. $436 \mathrm{p}$.

Deyholos MK, Cordner G, Beebe D, Sieburth LE. 2000. The SCARFACE gene is required for cotyledon and leaf vein patterning. Development 127:3205-3213.

Digby J, Wareing PF. 1966. The effect of applied growth hormones on cambial division and the differentiation of cambial derivatives. Ann Bot 30:539-548.

Edlund A, Eklöf S, Sundberg B, Mortiz T, Sandberg G. 1995. A microscale technique for gas chromatography-mass spectrometry measurements of picogram amounts of indole-3-acetic acid in plant tissues. Plant Physiol 108:1043-1047.

Eklöf S, Åstot C, Blackwell J, Moritz T, , Olsson Sandberg G. 1997. Auxin-cytokinin interactions in wild-type and transgenic tobacco. Plant Cell Physiol 38:225-235.

Esau K. 1965. Vascular differentiation in plants. New York: Holt, Rinehart and Winston. 160 p.

Fahn A. 1990. Plant anatomy. Oxford: Pergamon Press. 588 p.

Fegel CA. 1941. Comparative anatomy and varying physical properties of trunk, branch and root wood in certain northeastern trees. Bull NY State College of Forestry at Syracuse Univ, Vol 14, No 2b. Tech Publ 55:1-20.

Gourlay CW, Hofer JMI, Ellis THN. 2000. Pea compound leaf architecture is regulated by interactions among the genes UNIFOLIATA, COCHLEATA, AFILA, and TENDRIL-LESS. Plant Cell 12:1279-1294.

Groot EP, Meicenheimer RD. 2000. Comparison of leaf plastochron index and allometric analyses of tooth development in Arabidopsis thaliana. J Plant Growth Regul 19:77-89.

Hareven D, Gutfinger T, Parnis A, Eshed Y, Lifschitz E. 1996. The making of a compound leaf: genetic manipulation of leaf architecture in tomato. Cell 84:735-744.

Hobbie L, McGovern M, Hurwitz LR, Pierro A, Yang Liu N, Bandyopadhyay A, Estelle M. 2000. The axr6 mutants of Arabidopsis thaliana defective: a gene involved in auxin response and early development. Development 127:23-32.

Horner HT, Lersten NR, Wirth CL. 1994. Quantitative survey of sieve tube distribution in foliar terminal veins of ten dicot species. Amer J Bot 81:1267-1274.

Indig FE, Aloni R. 1989. An experimental method for studying the differentiation of vessel endings. Ann Bot 64:589-592.
Jacobs WP. 1952. The role of auxin in differentiation of xylem around a wound. Amer J Bot 39:301-309.

Koizumi K, Sugiyama M, Fukuda H. 2000. A series of novel mutants of Arabidopsis thaliana that are defective in the formation of continous vascular network: calling the auxin signal flow canalization hypothesis into question. Development 127:31973204.

Lersten NR. 1990. Sieve tubes in foliar vein endings: review and quantitative survey of Rudbeckia laciniata (Asteraceae). Amer J Bot 77:1132-1141.

Lersten NR, Brubaker CL. 1989. Paraveinal mesophyll, and its relationship to vein endings, in Solidago canadensis (Asteraceae). Can J Bot 67:1429-1433.

Lersten NR, Curtis JD. 1993. Paraveinal mesophyll in Calliandra tweedii and C. emarginata (Leguminosa; Mimosoideae). Amer J Bot 80:561-568.

Lev-Yadun S. 2000. Cellular patterns in dicotyledonous woods: their regulation. In: Savidge RA, Barnett JR, Napir R, editors. Cell and molecular biology of wood formation. Oxford: BIOS Scientific Publishers. p 315-324.

Mattsson J, Sung ZR, Berleth T. 1999. Responses of plant vascular systems to auxin transport inhibition. Development 126:29792991.

Meyerowitz EM. 1989. Arabidopsis, a useful weed. Cell 56:263269.

Nelson T. 1998. Polarity, vascularization and auxin. Trends Plant Sci 3:245-246. DOI: 10.1016/S1360-1385(98)01274-6

Nelson T, Dengler N. 1997. Leaf vascular pattern formation. Plant Cell 9:1121-1135.

Palni LMS, Burch L, Horgan R. 1988. The effect of auxin concentration on cytokinin stability and metabolism. Planta 174:231234

Plesch G, Störmann K, Torres JT, Walden R, Somssich IE. 1997. Developmental and auxin-induced expression of Arabidopsis prha homeobox gene. Plant J 12:635-647.

Poething RS. 1997. Leaf morphogenesis in flowering plants. Plant Cell 9:1077-1087.

Priestley JH, Scott LI. 1936. A note upon summer wood production in the tree. Proc Leeds Phil Soc 3:235-248.

Przemeck GKH, Mattsson J, Hardtke CS, Sung ZR, Berleth T. 1996. Studies on the role of the Arabidopsis gene MONOPTEROS in vascular development and plant cell axialization. Planta 200:229-237.

Raven PH, Evert RE, Eichhorn SE. 1999. Biology of plants, 6th ed. New York: Freeman and Company/ Worth Publishers. 944 p.

Roberts LW, Gahan PB, Aloni R. 1988. Vascular differentiation and plant growth regulators. Berlin: Springer-Verlag. $154 \mathrm{p}$.

Romano CP, Hein MB, Klee HJ. 1991. Inactivation of auxin in tobacco transformed with the indoleacetic acid-lysine synthetase gene of Pseudomonas savastanoi. Genes Dev 5:438-446.

Sachs T. 1969. Regeneration experiments on the determination of the form of leaves. Isr J Bot 18:21-30.

Sachs T. 1975. The control of the differentiation of vascular networks. Ann Bot 39:197-207.

Sachs T. 1981. The control of patterned differentiation of vascular tissues. Adv Bot Res 9:151-262.

Sachs T. 1989. The development of vascular networks during leaf development. Curr Top Plant Biochem Physiol 8:168-183.

Sachs T. 1991. Callus and tumor development. Sachs T. Pattern formation in plant tissues. Cambridge, New York: Cambridge University Press. p 38-55. 
Sachs T. 2000. Integrating cellular and organismal aspects of vascular differentiation. Plant Cell Physiol 41:649-656.

Sieburth LE. 1999. Auxin is required for leaf vein pattern in Arabidopsis. Plant Physiol 121:1179-1190.

Sundberg B, Uggla C, Tuominen H. 2000. Cambial growth and auxin gradients. In: Savidge RA, Barnett JR, Napir R, editors. Cell and molecular biology of wood formation. Oxford: BIOS Scientific Publishers. p 169-188.

Suzuki M, Yoda K, Suzuki H. 1996. Phenological comparison of the onset of vessel formation between ring-porous and diffuseporous deciduous trees in a Japanese temperate forest. IAWA J 17:431-444.

Telfer A, Poething RS. 1994. Leaf development in Arabidopsis. In: Meyerowitz EM, Somerville CR, editors. Arabidopsis.. Cold Spring Harbor Laboratory Press: Cold Spring Harbor Laboratory Press. p 379-401.

Tomlinson PT, Dickson RE, Isebrands JG. 1991. Acropetal leaf differentiation in Quercus rubra (Fagaceae). Amer J Bot 78:1570-1575.

Trewavas AJ. 1983. Is plant development regulated by changes in concentration of growth substances or by changes in the sensitivity to growth substances? TIBS 8:354-357.

Uggla C, Mellerowicz EJ, Sundberg B. 1998. Indole-3-acetic acid controls cambial growth in Scots pine by positional signaling. Plant Physiol 117:113-121.
Uggla C, Moritz T, Sandberg G, Sundberg B. 1996. Auxin as a positional signal in pattern formation in plants. Proc Natl Acad Sci USA 93:9282-9286. DOI: 10.1073/pnas.93.17.9282

Ullrich CI, Aloni R. 2000. Vascularization is a general requirement for growth of plant and animal tumours. J Exp Bot 51:1951-1960.

Wächter R, Fisher K, Gäbler R, Kühnemann F, Urban W, Bögemann GM, Voesenek LACJ, Blom CWPM, Ullrich CI. 1999. Ethylene production and ACC-accumulation in Agrobacterium tumefaciens-induced plant tumours and their impact on tumour and host stem structure and function. Plant Cell Environ 22:1263-1273. DOI: 10.1046/j.1365-3040.1999.00488.x

Wheeler EA, Baas P. 1991. A survey of the fossil record for dicotyledonous wood and its significance for evolutionary and ecological wood anatomy. IAWA Bull NS 12:275-332.

Yamamoto F, Angeles G, Kozlowski TT. 1987. Effect of ethrel on stem anatomy of Ulmus americana seedlings. IAWA Bull NS 8:3-9.

Zhang R, Zhang X, Wang J, Letham DS, McKinney SA, Higgins TJV. 1995. The effect of auxin on cytokinin levels and metabolism in transgenic tobacco tissue expressing an ipt gene. Planta 196:84-94.

Zhong R, Taylor JJ, Ye Z-H. 1999. Transformation of the collateral vascular bundles into amphivasal vascular bundles in an Arabidopsis mutant. Plant Physiol 120:53-64. 